\title{
COLECIONANDO FLORES DO MAL OU DA ANTOLOGIA COMO CRÍTICA
}

\section{Ricardo Meirelles}

\section{Introdução}

Como um desdobramento de um estudo mais abrangente sobre a história da recepção e da tradução dos poemas de Charles Baudelaire, este trabalho parte da reunião das traduções dos poemas do livro Les fleurs $d u$ mal, publicadas no Brasil em meio impresso - livros e periódicos - e procura refletir tanto sobre a relevância e o diálogo dessas traduções dentro da História da Literatura Brasileira, quanto sobre qual é a sua relação com esse clássico universal da literatura francesa.

Primeiro, em minha dissertação, Entre brumas e chuvas: tradução e influência literária (2003), e depois, em minha tese, Les fleurs du mal no Brasil: traduções (2010), discuti e considerei o papel da tradução poética dentro da História da Literatura Brasileira e a sua influência estética, observando específica e atentamente a recepção desses poemas escritos por Baudelaire.

Como o exercício crítico e historiográfico do antologista é muito semelhante ao do tradutor, o conceito de antologia como crítica é muito pertinente para o estudo da tradução de poesia. Sendo assim, procurei analisar o papel das antologias como manifestação crítica significativa de recepção dessa obra, especificamente observando a antologia publicada pelo poeta Cláudio Veiga - uma das mais originais em sua escolha, visto que esse tradutor foi um dos únicos brasileiros a escolher poemas do subconjunto "La mort", o último do livro de Baudelaire - e fazer algumas considerações sobre sua importância frente ao estudo da recepção de uma obra estrangeira.

Sendo assim, observei que a própria escolha de poemas, em uma antologia, já se constitui como crítica, oferecendo uma característica estética em sua recepção que também se pode verificar por meio da análise dos graus de homologia que essa escolha apresenta; ou seja, quando o antologista escolhe quais são os elementos que a vão compor, no caso de traduções de poemas, elege valores estéticos em sua recepção. Ao analisar uma antologia que traz um conjunto de poemas muito diferente daquele apresentado pelas outras ao longo 
do tempo, pude observar também a ampliação e a diversificação da leitura do livro de Baudelaire.

Diferentemente do acontecimento político, o literário não possui consequências imperiosas, que seguem existindo por si só e às quais nenhuma geração posterior poderá mais escapar. Ele só logra seguir produzindo seu efeito na medida em que sua recepção se estenda pelas gerações futuras ou seja por elas retomada - na medida, pois, em que haja leitores que novamente se apropriem da obra passada, ou autores que desejem imitá-la, sobrepujá-la ou refutá-la. A literatura como acontecimento cumpre-se primordialmente no horizonte de expectativa dos leitores, críticos e autores, seus contemporâneos e pósteros, ao experienciar a obra (Jauss, 1994, p. 26).

\section{A antologia como crítica}

Antologia (ou “coleção de flores", do grego), é uma coleção de trabalhos literários, geralmente poemas, agrupados por temática, autoria ou período. A palavra vem do nome da mais antiga coleção de poemas que se tem conhecimento, organizada pelo poeta grego Meléagro. Como se trata de uma coleção, o antologista, ou colecionador, se comporta como selecionador, colecionando apenas aquilo que lhe interessa, elegendo o que para ele é mais importante naquele momento, deixando de fora o que não atende aos seus critérios, sejam eles quais forem. Toda antologia, então, é crítica, pois parte de uma escolha prédeterminada e segue um conceito também pré-determinado, como esclarece Jamil Almansur Haddad:

O conceito deve atingir o espírito, o conteúdo, a ideologia. A transposição desconexa ou disparatada de textos não dá a antologia. O que confere em última análise o caráter antológico são as condições pessoais, puramente subjetivas, do antologista, e o como fazer a escolha, mais do que propriamente o fato de escolher, é o critério (Haddad, 1961, p. 16).

Fica claro que cada antologia é uma nova manifestação ou uma realização daquilo que coleciona, ou seja, a antologia também é o resultado de uma recepção daquele conjunto de textos; assim, variam as antologias, em cada época ou lugar: "Cada época tem a sua antologia, cada geração, cada movimento literário. Mudada a geração, a antologia muda" (Haddad, 1961, p. 29).

A antologia é a expressão de um momento estético, tão particular quanto uma tradução. "It is possible to associate the selection of poems in some anthologies with the literary tastes of specific social groups, at given points in time” (Kitel, 1995, p. XI). Ou 
seja, a antologia, assim como a tradução, também é o produto da recepção de uma comunidade interpretativa da qual faz parte o antologista, assim como o tradutor.

O antologista, como o tradutor, deve, antes de qualquer coisa, comportar-se como crítico e historiador, elegendo elementos que acredita significativos e relevantes, e que devem ser mantidos e propagados, em detrimento de outros aspectos que, naquele momento, não atendem às suas necessidades estéticas ou ideológicas.

Assim como os tradutores que apresentam uma introdução às suas traduções, justificando suas opções ou discutindo seus conceitos junto ao leitor, também os antologistas, como críticos, no mais das vezes fazem-no no intuito de garantir a compreensão dos conceitos defendidos por sua comunidade interpretativa.

O exemplo mais característico de que antologia é crítica tácita é dado por esses trabalhos de evolução literária em que, após larga dissertação do autor, se coloca a antologia exemplificatória: é o caso da Apresentação da Poesia Brasileira de Manuel Bandeira e Tendências do Lirismo Contemporâneo de Hernani Cidade, em que o texto crítico aparece como infra-estrutura de que a antologia é a afloração (Haddad, 1961, p. 32).

Pode-se ainda afirmar que a ideia que mais assemelha antologista e tradutor é o caráter extremamente pessoal de sua atividade, apresentando resultados únicos e específicos, que não poderiam ser repetidos mesmo pelo próprio executor em outro momento. Essa característica acaba recebendo dois tipos de manifestação pelo seu público receptor: por um lado, congratulações e avaliações positivas daqueles que compartilham e concordam com suas escolhas e conceitos; por outro, ataques e críticas negativas daqu eles que discordam das suas soluções e opções estéticas. Afinal, assim como uma tradução, a antologia é a manifestação de escolhas, de decisões:

Os gabaritos da antologia são necessariamente altos e não se deve levar à formulação legal o que é, em última instância, um defeito da antologia (o processo "tesoura e cola"), desprezando aquilo para o que a antologia penderá cada vez mais: o caráter individual, crítico da operação. E no verdadeiro antologista (sempre um crítico), se este quiser agir de acordo com sua autenticidade, arribará em obra necessariamente pessoal, tão pessoal que o próprio sentido da compilação antológica deverá ser resguardado por lei para que outro não venha a compilar da mesma maneira como já foi compilado, aparecendo então a figura da antologia plagiada. A antologia será pessoal por força dos atributos intelectuais do antologista, da sua sensibilidade, de seu gosto e de suas qualidades morais de isenção, que são em última instância as do juiz (Haddad, 1961, p. 55). 
Seria muito pertinente substituir as palavras "antologia" por "tradução" e "antologista" por "tradutor" na última frase da citação de Jamil Almansur Haddad: "A tradução será pessoal por força dos atributos intelectuais do tradutor, da sua sensibilidade, de seu gosto e de suas qualidades morais de isenção, que são em última instância as do juiz.” Toda escolha pressupõe uma ideologia que a orienta e que a antecede, elaborada e consolidada pelo meio da análise crítica.

Quando se comporta como historiador, o antologista, como o tradutor, procura garantir certa permanência na História da Literatura para aqueles textos que passaram por seus juízos críticos. Se então aplicarmos mais uma vez os conceitos da estética da recepção, também seria correto afirmar que a antologia, assim como uma tradução, realiza uma nova concretização da obra literária, "conferindo-lhe uma existência atual” (Jauss, 1994, p. 25). É o que também afirma Kitel:

While anthologies may be the most representative and most telling indicators of current preferences and of change in the tastes of individual, cultural elites or the general public, they also reflect changing attitudes toward the writings of the past in one country, and even toward the literary achievements of other nations (Kitel, 1995, p. xii).

Antologias gerais de cultura universal, sejam elas de literatura, filosofia ou mesmo de citações e frases, ou do que quer que seja, sempre serão parciais e opinativas, marcando fortemente um diálogo com a realidade para a qual é apresentada, contestando ou corroborando o pensamento vigente e, mais do que isso, refletindo-o implicitamente e, contudo, ocasionando sempre uma interferência nesse pensamento.

\section{Antologias de literatura estrangeira traduzida}

No caso específico de antologias de literatura estrangeira traduzida, essa crítica inevitável é elevada ao quadrado, visto que seu autor tem que realizar um duplo trabalho, definindo o seu conteúdo estrangeiro e original, quais autores e que textos escolher, e avaliando suas possíveis interpretações nacionais, quais traduções de um mesmo texto escolher, quando elas existem previamente, na composição de sua antologia.

Translated representatives of many cultures may be brought into direct juxtaposition and interference in a single anthology. In their aggregate, anthologies of translated literature 
may represent a country's translation culture at a given point in time (comparable to anthologies of Weltliteratur) or over an extended period (Kitel, 1995, p. xvi).

Ou seja, essas antologias são a expressão histórica de um diálogo cultural, em que as traduções são o seu registro concreto. Uma antologia de poetas de língua alemã, por exemplo, que não apresenta nenhum escritor judeu pode ser bastante eloquente historicamente, seja qual for a escolha dos poemas ou dos autores.

Em se tratando de antologias de literatura traduzida para a língua portuguesa, em geral, e, em particular, sobre poemas de Les fleurs du mal antologizados no Brasil, é interessante mencionar o estudo promovido por John Milton, também apresentado no livro de Kitel. Milton parte de duas obras de larga recepção na literatura brasileira para mostrar como é evidente, apesar de não mencionado explicitamente, o conjunto de conceitos que norteia as escolhas de cada antologista. Antes, ele apresenta ambos os livros:

The first part of this study will concentrate on two anthologies of translated poetry, Obras Primas da Poesia Universal (“Great Works of World Poetry”), ed. Sérgio Milliet, 1955, and Poesia ("Poetry"), ed. Ary de Mesquita, 1950. Both anthologies contain a wide selection of world poetry in translation together with poetry in Portuguese from both Brazil and Portugal. Neither anthology contains the original versions of the translated poems (Milton, 1995, p. 127).

Depois, ao longo do texto, procura deixar claro quais são os conceitos e a ideologia que se manifestam na observação do conjunto dos textos escolhidos, trazendo alguns comentários do próprio antologista, que acabam servindo como guia para o seu entendimento. Primeiro, Milton trata da antologia de Sérgio Milliet:

Milliet's choice of authors is wide-ranging and catholic. No author is given more than eight pages. His main limitation, he says, was that of choosing translations which already existed in Portuguese. [...] Although the majority of authors included could be loosely placed under a Modernist label [...] Milliet's main intention seems to be to present an anthology of poetry weighted towards Modernism but not consisting entirely of Modernist poets. He doesn't forget the title - Obras-Primas da Poesia Universal ("Great Works of World Poetry"). (Milton, 1995. p. 128)

Ou seja, fica claro para o leitor que o autor da antologia tende a privilegiar certa corrente estética ou escola literária com a qual tem mais empatia, sejam quais forem seus 
motivos; contudo, procura também ser amplo e equilibrado, optando por traduções já publicadas, reconhecendo uma prévia recepção daqueles textos.

Por outro lado, a antologia de Ary de Mesquita também se mostra bastante peculiar, ainda que procure se guiar por um outro conjunto de conceitos e valores, diferentes dos de Milliet, principalmente quando inclui traduções próprias de textos que acredita imprescindíveis para assegurar a abrangência e a relevância de sua obra, a antologia, o que acaba tornando o resultado ainda mais discutível, como se pode ler nos comentários de Milton:

Mesquita omits any poet whose style is very different from the Parnassian norms. There is no Dickinson, no Whitman, even no Keats. And to ensure quality control, Mesquita makes many of the translations himself. They reflect the form of the original at all costs (Milton, 1995. p. 129).

Comparando ambos os conjuntos de conceitos apresentados pelas antologias, Milton traz ainda comentários sobre alguns tradutores que pertenceram a correntes teóricas e críticas que por muito tempo serviram como base para a avaliação do que seria mais representativo dentro da literatura brasileira, mostrando dois conjuntos concorrentes tanto teoricamente quanto na sua realização prática. Fica bastante clara, essa concorrência, quando opõe as opiniões de escritores a elas ligados.

De certa forma, Milton parece discordar das opções expressas na segunda antologia criticada, a de Ary de Mesquita, quando afirma que as traduções escolhidas seguem parâmetros e conceitos encontrados na escola literária brasileira chamada de Geração de 45, notoriamente reconhecida pelo seu caráter parnasiano, que apreciava mais os rigores formais em detrimento daquela estética mais livre, promovida pelos autores ligados ao Modernismo, ainda em alta conta dentro do panorama da literatura brasileira, tecendo os seguintes comentários:

Jorge Wanderley finds the translations of the Geração de 45 characterised by a formal rigour and perfection: the formal qualities of the original poem must appear in the translation; a translated sonnet must keep its strict original form (Milton, 1995. p. 129).

Broadly speaking the style of this group of translations follows the parameters set out for the translations of the Geração de 45 by Jorge Wanderley. Apart from the translations of Oswaldino Marques, whose translations are literal and prosaic, the translators included in this group try to make a 'facilitating' translation which will follow the formal contours of 
the original. Sometimes the form of the original is rigidly obeyed, as in the translations of José Lino Grünewald, and sometimes the verse form of the original is adapted to a more suitable Portuguese form. The classic example is the translation of the English iambic pentameter into the Portuguese alexandrine, as in many of the translations of Péricles Eugênio da Silva Ramos (Milton, 1995. p. 132).

O que fica bem claro e merece relevância nesses comentários é a inevitável adaptação executada por esses tradutores, mesmo em nome do maior e mais absoluto rigor formal possível, quando Milton chama a atenção para o fato de que eles acabam também se rendendo às transformações tradutórias, por exemplo, quando traduzem pentâmetros iâmbicos ingleses em alexandrinos portugueses, por se depararem com a "intransponível" barreira dos sistemas linguísticos diferentes: a língua inglesa tem características linguísticas que não podem ser reproduzidas em língua portuguesa simplesmente porque não existem opções similares.

Isso muito interessa, pois acaba libertando ou conduzindo o tradutor a empregar soluções diversas e inusitadas, mesmo que em nome do maior rigor formal possível, ou seja, se for admitida a diferença entre os sistemas lingüísticos, há também de ser admitida a diferença do conjunto de soluções escolhidas por cada tradutor.

\section{Les fleurs du mal e as Antologias de Poesia Francesa}

Tratando-se especificamente do livro de Charles Baudelaire, Les fleurs du mal, poder-se-ía também observar como e quando o conjunto de conceitos predominantes em uma determinada época ou defendidos por um determinado tradutor definiu tanto a escolha de poemas exclusivos, quanto o modelo tradutório empregado para traduzi-los. Ou seja, os tradutores que escolheram apenas alguns poemas, entre os cento e sessenta do livro francês, perfizeram também a sua antologia de poemas, operando duplamente como críticos e historiadores.

Já em 1917, Alvaro Borges dos Reis lança aquela que é, salvo engano, a primeira antologia exclusiva de poetas franceses publicada no Brasil, Musa francesa, trazendo três poemas de Baudelaire: "O albatroz", "Uma carniça", e "O tonel do ódio".

Em 1936, Guilherme de Almeida publica a antologia Poetas de França, livro que muito circulou e ainda circula, estabelecendo, de certa forma, um cânone da recepção da poesia francesa até então. Nesse livro já aparecem dois poemas de Baudelaire: "A 
cabeleira", ("La chevelure") e "O convite à viagem" (“L’invitation au voyage”). Na introdução, no intuito de esclarecer os seus leitores, o poeta apresenta sua própria definição do que é tradução e qual é a sua conduta:

Traduzir? - O dicionário diz: "Verter, trasladar de uma língua para outra". Mas não pode ser só isso. Quem escreve e, principalmente, quem escreve versos sabe muito bem como nasce a ideia: com um ritmo anterior, imperioso e intrínseco, como uma criancinha com um destino, um corpo com uma alma. [...] Mas esse ritmo — primeiro como Deus, impulso inicial de toda poesia - não é simples medida, metro, contagem de sílabas, corte de verso. Vai além da matéria e dos sentidos. [...] Poder-se-á traduzir, verter, trasladar de uma língua para outra esse complexo-simples que é um ritmo?

Ora, traduzir, nesse caso, seria antes "reproduzir". "Reproduzir", no sentido autêntico, primitivo do termo: "re"-"produzir", quer dizer, produzir de novo, ou seja, sentir, pensar e dizer como o autor e com o autor.

É o que este livro tenta fazer.

Apesar do rigor formal perseguido em todas as traduções apresentadas, Guilherme de Almeida se sente seguro ao afirmar que pretende mesmo "produzir de novo" aqueles ritmos encontrados nos textos estrangeiros. Mais tarde, em 1944, ele mesmo publicará uma antologia apenas de poemas de Baudelaire, intitulada Flores das Flores do mal, somando mais dezenove aos dois anteriores, num total de vinte e um poemas. O título já deixa claro a ação da escolha: o poeta que caminha com tranquilidade dentro do jardim de Baudelaire e colhe apenas um bouquet daquilo que mais lhe agrada.

Em 1938, Osório Dutra também lança uma antologia exclusiva de poemas de Les fleurs du mal, intitulada Cores, sons e perfumes, apresentando a tradução de trinta e oito poemas; livro de altíssima qualidade gráfica, produzido pelo poeta João Cabral de Melo Neto em sua editora $\mathrm{O}$ Livro Inconsútil - que existiu enquanto era funcionário do consulado brasileiro da cidade de Barcelona (Espanha) - mas de pouca qualidade estética, segundo o próprio julgamento do editor, confidenciado ao bibliófilo José Mindlin que me apresentou essa informação ao permitir que lesse seu exemplar, hoje raríssimo. A antologia de Dutra, além de não apresentar uma escolha original de poemas ou um texto introdutório discutindo algum critério poético ou literário, trazia traduções que seguiam o projeto tradutório tradicional, ou seja, parnasiano, não colaborando expressivamente com uma nova leitura nem ampliando aquela já existente.

Já em 1964, foi publicada outra antologia exclusiva de poemas de Baudelaire: Algumas "Flores do mal”, de Mauro Mendes Villela, trazendo dezessete poemas — "O 
albatroz", "Bênção", "O homem e o mar”, "O sino fendido", "Elevação”, "Reversibilidade”, “A música", “O inimigo”, "Recolhimento”, “Correspondências”, "Canto de outono", "Spleen", "Castigo do orgulho", "O relógio", "Harmonia da tarde", “As velhinhas", “A beleza” - e um curtíssimo prefácio de Oscar Mendes, no qual destaca que o tradutor "reúne neste volume alguns dos poemas baudelairianos de seu agrado." (Villela, 1964, p. 3)

Outras antologias de poesia francesa também circularam fartamente, decerto subsidiadas pelo incremento da produção de livros que se deu a partir da década de 1930. Os livros de Olegário Mariano, Antologia de tradutores, de 1933, e Raimundo Magalhães Junior, Antologia de poetas franceses: do século XV ao século XX, de 1950, publicados no Rio de Janeiro, em grandes tiragens e em várias edições, muito contribuíram para a divulgação da poesia de Baudelaire no Brasil, sendo que o primeiro trazia apenas cinco poemas — "Elevação", traduzido por Eduardo Guimaraens, "Tristezas da lua", traduzido por Martins Fontes e "Tristezas da lua", "Alba espiritual" e "O sino rachado", traduzidos por Felix Pacheco.

A segunda antologia citada, de Raimundo Magalhães Junior, contudo, já trazia uma coleção mais considerável de poemas de Baudelaire, somando vinte e cinco, tornando-se a maior coleção de poemas de Les fleurs du mal publicados no Brasil até então (1950); em sua coleção, retomando traduções já publicadas, apresenta uma coleção de diversos tradutores, os quais seriam Olavo Bilac, com o poema "A cabeleira"; Guilherme de Almeida, com "O albatroz", "A alma do vinho" e "Remorso póstumo", o português Delfim Guimarães, com "Os gatos", Teófilo Dias, com "O espectro" e "Fonte de sangue”, Osório Dutra, com "Perfume exótico", Eduardo Guimaraens, com "Elevação", Martins Fontes, com “Tristezas da lua”, Lopes Filho, com “A giganta”, Felipe D’Oliveira, com "Invitation au voyage", Paulo César Pimentel, com seis poemas: "Um Morto Alegre", "Luminares (Faróis)", "Encontro de Rua (A Uma Passante)", "O Sino Partido", "Litanias de Satã”, "Intimidades (Conversa)", Venceslau de Queiroz, com "De profundis clamavi” e "O céu (A tampa)", Álvaro Borges dos Reis, com “ A carniça”, "O tonel do ódio”, e Fontoura Xavier, com "O frasco " e "O sol”.

Essa antologia também é emblemática no percurso da recepção de poemas de Baudelaire como um registro da influência da literatura francesa em nossos escritores, visto 
que o autor procurou colecionar um grande número tanto de autores estrangeiros quanto de brasileiros e portugueses, tradutores. Dentre os cento e onze poetas franceses colecionados, Baudelaire é o que tem o maior número de poemas escolhidos, sendo seguido por Victor Hugo e Alphonse de Lamartine, ambos com vinte e três poemas, e Paul Verlaine, com dezenove poemas, autores franceses bastante traduzidos até então, mas o antologista procura também ser abrangente, quando apresenta outros autores ainda inéditos em língua portuguesa, como explica no seu prefácio:

Como alguns poetas dignos desta antologia não estavam traduzidos, tomamos a ousada iniciativa de verter-lhes pobremente um poema ou outro, para que aqui pudessem figurar. É o caso de Charles d'Orléans. É o caso de Cyrano de Bergerac, etc. (Magalhães Junior, 1950, p. 6-7).

É interessante que o antologista já declara ousada essa iniciativa de traduzir alguns poetas, ainda que precariamente, para que pudessem figurar na sua antologia. Essa atitude reflete o nível de comprometimento de seu autor com os conceitos eleitos previamente e que nortearam o seu trabalho. Ainda no seu prefácio, Magalhães Junior justifica sua obra com motivos simples e pertinentes, procurando garantir a compreensão e a cumplicidade dos leitores: primeiro, uma nova antologia de poesia francesa se fazia necessária, visto que as anteriores, como as de Guilherme de Almeida e Olegário Mariano, estavam esgotadas; depois, elas seriam insuficientes e pouco abrangentes, limitadas tanto no número de autores quanto no de textos apresentados; por fim, as antologias eram um sucesso de vendas, motivo que é apresentado na introdução escrita por Michel Simon:

Outra razão da abundância das traduções francesas no Brasil deve ser identificada no rápido desenvolvimento da classe média. Esta não tem, infelizmente, os mesmos lazeres para estudar o francês com o apuro dos meios aristocráticos do século XIX, mas não quer ficar no desconhecimento da literatura francesa (Magalhães Junior, 1950, p. iii).

Ainda nessa introdução, seu autor faz afirmações controversas, por exemplo, quando diz que "Um poema não se traduz", sua primeira frase, e que "A fidelidade não é necessária". Traduzir poesia é uma recreação, um passatempo, não pode ser levado a sério, diz o autor. "A expressão 'correspondência' seria mais corretamente empregada do que ‘tradução'. Porque o poeta escolhe para traduzir um espírito congênere”, ou seja, tradução 
de literatura ou de poesia só se dará satisfatoriamente e inevitavelmente se for feita por identificação estética entre tradutor e traduzido, o que justifica a apresentação do maior número possível de tradutores diferentes.

Antes do lançamento da primeira edição completa de Les fleurs du mal no Brasil, em 1958, por Jamil Almansur Haddad, os poemas de Baudelaire circulavam bastante dentro da literatura brasileira, como vinha fazendo com certa consistência desde o seu lançamento francês, em 1857. Pode-se afirmar que as antologias de poesia francesa que antecederam o livro de Haddad não só prepararam o mercado editorial para a aceitação de tal obra, como diversificaram e ampliaram a leitura e a interpretação daquele livro, garantindo a continuidade de sua divulgação. Contudo, essa divulgação é parcial e opinativa, visto que promoveu uma escolha específica dentro de uma extensa gama de poemas diversos, não só na temática, mas também nos aspectos formais ou circunstanciais.

\section{A Antologia de Poesia Francesa de Cláudio Veiga}

Entre outras diversas obras publicadas recentemente, sobre as quais não irei me deter, a antologia de Cláudio Veiga, publicada posteriormente ao livro de Haddad, chama a atenção por conta da sua republicação em determinados momentos ao longo do tempo, passando por pequenas modificações, especificamente quanto aos poemas de Baudelaire apresentados, que podem parecer significativas, se observadas mais atentamente.

Entre a edição de 1972 da sua Mini antologia bilíngue da poesia francesa, publicada em Salvador (Bahia), e a edição de 1991 da sua Antologia da poesia francesa, publicada no Rio de Janeiro (Rio de Janeiro), há um aumento significativo do número de poemas de Baudelaire: de dois — "Correspondances" e "Recueillement" — passam a ser oito - adicionando "Les chats", "La cloche fêlée", "Les aveugles", "Harmonie du soir", "Spleen", "Les petites vieilles". No entanto, em 1999, é o acréscimo de três poemas que se dá na segunda edição da mesma antologia que merece o nosso destaque.

Esses três últimos poemas acrescentados à antologia — "La mort des amants", "La mort des pauvres", "La mort des artistes" - se destacam do conjunto anterior, apresentando uma temática específica - a morte - pouco ou nada procurada anteriormente pelos tradutores brasileiros em geral, sendo que o último poema dos três foi traduzido especificamente apenas pelo antologista em questão, Cláudio Veiga. 
Essa inclusão dos três poemas da subdivisão "La mort" é relevante no sentido que se mostra atenta a uma ampliação expressiva da leitura dos poemas de Baudelaire, possibilitando ao leitor mais uma alternativa às três traduções integrais, chamando sua atenção para uma subdivisão pouco especificamente traduzida no Brasil.

Cláudio Veiga, ao incluir em sua antologia de poesia francesa esses poemas emblemáticos, "La mort des amants", "La mort des pauvres", "La mort des artistes", mostra uma atitude crítica que procura ampliar e atualizar a leitura do livro francês em língua portuguesa no Brasil. Essa subdivisão, "La mort", foi muito pouco procurada pelos poetas brasileiros, sendo que, além da tradução de Veiga do poema "La mort des artistes", há apenas as dos três tradutores que traduziram o livro todo; para os outros dois poemas, "La mort des amants" e "La mort des pauvres", há também traduções de Dante Milano, publicadas em 1979, e uma de Juremir Machado Silva, do poema "La mort des amants", publicada em 2003; e, finalmente, do poema "La mort des pauvres", existem as traduções de Clodomiro Cardoso, de 1933, e de Osório Dutra, de 1938, publicadas em obras de pouca circulação.

Ou seja, Veiga não só aumenta o número de poemas de Baudelaire em sua antologia, reconhecendo seu mérito e sua importância renovada contemporaneamente, mas também amplia o alcance do leitor dentro da temática desenvolvida na subdivisão "La mort", chamando a sua atenção para o fato de que Les fleurs du mal não trata apenas do embate entre spleen e ideal, mas também o seu desdobramento, o seu desenvolvimento e as consequências desse embate.

Esse subconjunto, "La mort", que já fazia parte da primeira edição do livro francês, traz poemas que apresentam uma conclusão ou desfecho para o percurso do poeta ilustrado ao longo do livro; se o "percurso" desenvolvido pelo poeta ao longo de Les fleurs du mal deve ser completado, o seu fim muito pode dizer sobre o seu todo, principalmente no caso desse livro. O que Cláudio Veiga oferece, com a tradução desse subconjunto, é uma possibilidade de acompanhamento dessa conclusão, e de seus valores, pelo leitor brasileiro.

Assim como pode fazer muita falta a imagem da "floresta de símbolos" encontrada no poema "Correspondances" para uma leitura mais abrangente de Le fleurs du mal, ter acesso aos poemas de seu último subconjunto pode ser determinante na sua apreensão pelo leitor e no desenvolvimento estético da sua recepção. 


\section{Sobre a morte dos artistas}

É preciso que o leitor saiba e tenha acesso a esse subconjunto de poemas, "La mort", para ampliar e desenvolver a sua leitura dos subconjuntos precedentes, principalmente o primeiro, "Spleen et ideal". O conjunto desses poemas sobre a morte conserva seu caráter de conclusão, mesmo depois, na edição de 1861, quando são sucedidos pelos poemas "Le rêve d'un curieux" e "Le voyage".

Esses valores podem ser encontrados principalmente no terceiro poema, "La mort des artistes", publicado por Baudelaire primeiro em 1851, na revista Le Messager de l'Assemblée - sendo o que fez parte da edição de 1857 bastante modificado - e colocado como o centésimo e último poema da primeira edição do livro. Ele questiona a ação efetiva do trabalho do artista, em oposição a um destino inexpugnável que se sobrepõe a qualquer atitude mais racional. Trata-se da luta eterna entre o artista e o anjo da morte, tema recorrente em toda a obra de Baudelaire, como afirma Pichois: "Elle constitue la vie même de l'artiste qui devine par-delà les apparences les traits resplendissants du Type platonicien qu'il rêve, mais dont il peut seulement dérober des fragments." (Baudelaire, 1975, p. 1090).

Essas questões, caras à poesia parnasiana, que tem o trabalho e o esforço árduo como meio para alcançar a beleza pura, põem em xeque esse ideal estético, mostrando sua ineficácia e sua impotência, visto que o seu fim, sua meta, é de natureza mística, elaborada fora da realidade. Sua ação, seja ela sutil ou demolidora, resulta apenas em ainda mais sofrimento, visto que seu fim é único e inevitável, o fim que aguarda a todos os seres, inclusive aos artistas, apesar da sua relutância e das suas tentativas de ludibriá-lo. "La recherche de la Beauté suppose un effort - celui de Prométhée, celui d'Icare - qui constitue au sens éthique une valeur. Cette valeur a nom: dignité", afirma Pichois (Baudelaire, 1975, p. 1090). É esse valor, a dignidade, é que o poeta toma para si como o principal em termos tanto éticos quanto artísticos e estéticos, capaz de dar sentido à morte inevitável: o poder do artista frente a vida é o poder de morrer com dignidade.

A morte é, na verdade, o único incentivo ao trabalho do poeta: só ela, um sol novo, é capaz de desabrochar flores no cérebro dos artistas. Aceitá-la é aceitar a realidade da vida e aceitá-la com dignidade é o que diferencia o artista do homem comum; seria ainda uma 
atitude digna abandonar as esperanças que viriam por ventura daquele capitólio, ou seja, na arte mais antiga, a esperança só pode vir da morte.

Nesse subconjunto, "La mort", a conclusão é a constatação de que a única esperança é a morte; e o poeta, por aceitar com dignidade esse fato irremediável acaba, de certa forma, sendo um vencedor, tomando a própria morte como alimento para a sua arte, pois a verdadeira beleza, para Baudelaire, está além do mundo, já que a arte tem uma necessidade mística e metafísica que se manifesta apenas como uma série de esforços, ou seja, não importa o número de tentativas arriscadas, há ou não há a possibilidade de atingir a qualquer momento a sua meta, alcançada completamente ao acaso, apesar de o poeta se envolver em cálculos que, contudo, não garantem nunca a possibilidade segura de atingir o seu objetivo. Esse objetivo é fortemente desejado, entretanto, ainda que o artista sinta que existe entre ele e a beleza ideal muitas afinidades e muitos desencontros.

Por conseguinte, o sentido da própria arte como ideia de morte é um apontamento para o absoluto, consciente ou inconscientemente. Baudelaire indica que ela incorpora um recurso que não tem muito de intensidade, ele mostra que a arte faz justiça àqueles que trabalham, apesar das críticas, da negação e dos ciúmes dos consagrados por seus contemporâneos. Em sua poesia, manifesta-se o poder de criação que domina o mundo dos mortais. Inevitavelmente, ele capta o espírito indescritível propício à expressão das grandes obras-primas. Há de se pensar que a criação real se apropria de uma essencialidade e de uma realidade que abrange a concepção proustiana do tempo.

\section{A antologia como uma nova proposta de tradução}

No caso específico do livro de Baudelaire, é importante lembrar as considerações que Álvaro Faleiros faz sobre o tradutor/antologista Juremir Machado Silva e seu livro Flores do mal, o amor segundo Baudelaire, lançado em 2001, no qual apresenta nada menos do que oitenta e um poemas traduzidos de Les fleurs du mal de uma forma inusitada até então, tendo usado como critério de escolha "exclusivamente a paixão e o caos" (Silva, 2001, p. 5). Em relação à leitura simultânea das traduções de Haddad, Junqueira e Guilherme de Almeida com as de Juremir Machado Silva, afirma Faleiros:

No que concerne aos três primeiros tradutores aqui comentados e à reação de Juremir Machado de Silva [sic], esta última sugere uma espécie de esgotamento de um determinado 
modelo e o surgimento de uma nova proposta de tradução, ou seja, contamos hoje, com um conjunto considerável de traduções dos poemas de Baudelaire que, muitas vezes, em detrimento das imagens, fixaram-se nos aspectos formais, produzindo um Baudelaire mais rigoroso e frio, de índole parnasiana. Com sua atitude irreverente, Silva tenta outra via que, com seu ímpeto pioneiro, chega de forma ainda rude e desajeitada, mas abre a primeira picada numa senda ainda inexplorada no Brasil. (Faleiros, 2007, p. 261)

Nesse sentido, a leitura que se deseja, hoje em dia, é a da simultaneidade, que atinja essa “cadeia de recepções", principalmente em questões de tradução, conceito estreitamente ligado à ideia de comunicação e interação; a leitura do máximo possível de traduções de um texto só pode ser profícua e benéfica, completando-se mutuamente enquanto aproxima e afasta o leitor ora do texto original, ora da própria literatura, admitindo que esse processo não é nunca estático, é sempre uma dinâmica dialética entre levar o leitor local à cultura estrangeira e trazer o texto estrangeiro à cultura local, não se pode optar por uma dessas travessias, a tradução é o simultâneo ir e vir.

A implicação histórica manifesta-se na possibilidade de, numa cadeia de recepções, a compreensão dos primeiros leitores ter continuidade e enriquecer-se de geração em geração, decidindo, assim, o próprio significado histórico de uma obra e tornando visível sua qualidade estética (Jauss, 1994, p. 23).

Ao traduzir os poemas do subconjunto "La mort", Cláudio Veiga elege esses outros elementos como fundamentais para a apreciação e a recepção mais consistente das poesias de Baudelaire. Apesar de seu projeto tradutório ainda ser muito tradicional, seu projeto de antologia acaba compensando suas escolhas, que merecem destaque, no mínimo, por serem mais originais que as apresentadas até então. O que se pode concluir é que um novo projeto de antologia pode servir de alavanca para uma nova leitura do antigo e tradicional projeto tradutório empregado para abordar os poemas de Les fleurs du mal.

\section{Referências bibliográficas:}

ALMEIDA, G. de. Flores das 'Flores do mal'. Rio de Janeiro: José Olympio, 1944. . Poetas de França. Rio de Janeiro, 1936.

BAUDELAIRE, C. As flores do mal. Tradução de Ignácio de Souza Moitta. Belém: Conselho Estadual de Cultura, 1971. 
As flores do mal. Tradução, introdução e notas de Jamil Almansur Haddad.

São Paulo: Difel, 1958. As flores do mal. Tradução, introdução e notas de Ivan Junqueira. Rio de Janeiro: Nova Fronteira, 1985. (Poesia de todos os tempos) . Oeuvres complètes. Texte établi, présenté et annoté par Claude Pichois. Paris: Gallimard, 1975.

CARDOSO, C. Álbum inédito das traduções de C. C. Biblioteca Pública Municipal de São Paulo "Mário de Andrade".

DUTRA, O. Cores, perfumes e sons. Barcelona: O livro inconsútil, 1938.

FALEIROS, A. A crítica da retradução poética. In: Itinerários, FCL/UNESP/CAr, Araraquara: n. 28, 145-158, jan./jun. 2009.

Sobre uma não-tradução e algumas traduções de "L'invitation au Voyage" de Baudelaire. In: Alea: Estudos Neolatinos. PPGLN/FL/UFRJ, v. 9, n. 2, 250-262, julho/dezembro de 2007.

HADDAD, J. A. e BUZAID, A. Defesa e ilustração da antologia. São Paulo: Companhia Editora Nacional, 1961.

JAUSS, H. R. A história da literatura como provocação à teoria literária. Trad. Sérgio Tellaroli. São Paulo: Brasiliense, 1994.

KILLICK, R. Baudelaire's versification: conservative or radical? In: LLOYD, Rosemary (org.). The Cambridge companion to Baudelaire. Cambridge: Cambridge University Press, 2006. p. 51-68.

KITEL, H. An introduction to incipient research. In: KITEL, H. (org.) International anthologies of literature in translation. Göttingen, Erich Schmidt, 1995. p. i-xxvii.

LARANJEIRA, M. Poética da tradução. São Paulo: Edusp, 1993. (Criação e Crítica, v. 12)

LIMA, L. C. A Literatura e o leitor. Textos de estética da recepção. Hans Robert Jauss et al.; coordenação e tradução de Luiz Costa Lima. Rio de Janeiro: Paz e Terra, 1979. . Teoria da literatura em suas fontes. $2^{\mathrm{a}}$ ed. revista e ampliada. Rio de Janeiro: Francisco Alves, 1983.

MAGALHÃES JUNIOR, R. Antologia de poetas franceses: do século XV ao século XX. Rio de Janeiro: Tupy, 1950.

MARIANO, O. Antologia de tradutores. Rio de Janeiro: Guanabara, 1933. 
MEIRELLES, R. Entre brumas e chuvas: tradução e influência literária. Dissertação (mestrado) - Universidade Estadual de Campinas, Instituto de Estudos da Linguagem: Campinas, 2003. . Les fleurs du mal no Brasil: traduções. 2010. Tese (doutorado) - Faculdade de Filosofia, Letras e Ciências Humanas. Universidade de São Paulo, São Paulo, 2010. MILANO, D. Poesia e prosa. Organização de Virgílio Costa. Rio de Janeiro: Civilização Brasileira, Núcleo Editorial da UERJ, 1979. (Coleção Vária).

MILTON, J. “Modernists versus Neo-Parnassians in translated anthologies in Brazil”. In: KITEL, H. (org.) International Anthologies of Literature in Translation. Göttingen, Erich Schmidt, 1995. p. 126-133.

REIS, Á. B. dos. Musa francesa. Apresentação de Pethion de Villar. Salvador: Reis, 1917.

SILVA, J. M. da. Flores do mal, o amor segundo Baudelaire. Porto Alegre: Sulina, 2001.

VALÉRY, P. Variedades. Organização e introdução de João Alexandre Barbosa, tradução de Maiza Martins de Siqueira e posfácio de Aguinaldo Gonçalves. São Paulo: Iluminuras, 1991.

VEIGA, C. Mini antologia bilingue da poesia francesa. Salvador: Livraria Universitária, 1972. Antologia da poesia francesa. Rio de Janeiro: Record, 1991 . Antologia da poesia francesa (do século IX ao século XX). $2^{\mathrm{a}}$ ed. ampliada. Rio de Janeiro: Record, 1999.

VILLELA, M. M. Algumas “Flores do mal”. Belo Horizonte: Bernardo Álvares, 1964.

\section{Anexo}

\section{A morte dos amantes}

Nós teremos um leito perfumado, Divãs que sepulturas lembrarão, Estranhas flores num buquê variado, Nascidas para nós noutra amplidão.

Um resto de calor enfim usado, As duas almas dois faróis serão, Que suas luzes haverão passado Aos espelhos de nosso coração. 
E num céu cor-de-rosa e azul do poente, Permutaremos um clarão somente,

Como um soluço, cheio de saudade,

Pouco depois, um Anjo, abrindo as portas,

Vem animar, alegre e com bondade,

Os espelhos sem luz e as chamas mortas.

\section{A morte dos pobres}

É a Morte que consola e alimenta a jornada;

É o alvo desta vida, exclusiva esperança,

Elixir que nos torna a vida arrebatada,

$\mathrm{E}$, em nosso caminhar, nos dá perseverança.

Em pleno temporal, na neve e na geada, É no negro horizonte o clarão da bonança, No registro da vida, a famosa pousada, Onde alguém se alimenta, adormece e descansa.

É o Anjo que detém, nos dedos milagrosos, O sono e a inspiração dos sonhos mais ditosos, E que o leito refaz dos pobres desvalidos;

É dos Deuses a glória, o sagrado celeiro, É a riqueza do pobre e seu país primeiro, É a porta que conduz aos Céus desconhecidos!

\section{A morte dos artistas}

Quantas vezes eu devo enfiar a fantasia, Tua fronte beijar, triste Caricatura?

Para o alvo não errar, de mística feitura, Quantos dardos perder, fazendo a pontaria?

Em vãs complicações nossa alma se esvazia, E vamos demolir muita forte armadura, Antes de contemplar a grande Criatura, Cujo anseio infernal nos enche de agonia!

Há mais de um que jamais o seu Ídolo alcança, E este escultor maldito, as injúrias sofrendo, No peito e na cabeça os punhos vai batendo:

Seu triste Capitólio é uma só esperança!

É que a Morte lembrando as luzes matutinas Lhe faça despontar as flores cerebrinas! 